\title{
Úlceras nos membros inferiores de pacientes diabéticos: mecanismos moleculares e celulares
}

\author{
Lower limb ulcers in diabetic patients: molecular \\ and cellular mechanisms
}

\section{Pedro Ribeiro Soares de Ladeira ${ }^{1}$, Cesar Isaac ${ }^{2}$, Andre Oliveira Paggiaro³ Elisabeth Mie Hosaka ${ }^{4}$, Marcus Castro Ferreira ${ }^{5}$}

Ladeira PRS, Isaac C, Paggiaro AO, Hosaka EM, Ferreira MC. Úlceras nos membros inferiores de pacientes diabéticos: mecanismos moleculares e celulares/Lower limb ulcers in diabetic patients: molecular and cellular mechanisms. Rev Med (São Paulo). 2011 jul.-set.;90(3):122-7.

\begin{abstract}
RESUMO: Diabetes mellitus representa um grupo de desordens metabólicas heterogêneas que surge como resultado de hiperglicemia por déficit na secreção e/ou ação da insulina. Sua prevalência e gastos relacionados vêm crescendo no mundo todo. Entre suas complicações de longo prazo, a que mais gera admissões hospitalares é a úlcera de membros inferiores. Estas feridas frequentemente tornam-se crônicas devido a uma série de aberrações moleculares e celulares do processo de cicatrização, sendo as principais: alta concentração de metaloproteinases (MMPs), neuropatia, alta probabilidade de infecção e resposta inflamatória não fisiológica, estresse oxidativo, formação excessiva de AGEs (produtos de glicoxidação avançada), neoangiogênese deficiente, desbalanço entre metabolismo e entrega de nutrientes, concentrações inadequadas de fatores de crescimento e reguladores de expressão gênica, e anormalidades celulares. Com melhor compreensão científica desses eventos e da cicatrização fisiológica, novas abordagens da patologia poderão fornecer resultados mais satisfatórios ao seu tratamento.
\end{abstract}

DESCRITORES: Pé diabético; Cicatrização; Ferimentos e lesões; Diabetes mellitus; Produtos finais de glicosilação.

\begin{abstract}
Diabetes depictures a heterogeneous group of metabolic disorders that arise as a result of hyperglycemia due to the deficit of secretion and/or insulin action. Its prevalence and related costs have been growing around the world. Among its long-term complications, foot ulcer is the one that generates more hospital admissions. These wounds often become chronic due to a series of molecular and cellular aberrations of the healing process, being the main mechanisms the following: high concentrations of matrix metalloproteinases (MMPs), neuropathy, high probability of infection and non-physiological inflammatory response, oxidative stress, excessive formation of AGEs (advanced glicoxidation end-products), deficient neoangiogenesis, imbalance between metabolism and nutrient delivery, inadequate concentrations of growth factors and gene expression regulators, and cellular abnormalities. With better scientific understanding of these events and physiological healing, new approaches to disease can provide more satisfactory results to the treatment.
\end{abstract}

KEYWORDS: Diabetic foot; Wound healing; Wounds and injuries; Diabetes mellitus; Glycosylation end products, advanced.

\footnotetext{
1. Acadêmico do curso de Medicina da Faculdade de Medicina da Universidade de São Paulo - FMUSP.

2. Médico responsável pelo Laboratório de Pesquisa em Cultura Celular e Feridas - LIM 04 HCFMUSP.

3. Médico responsável pelo Banco de Tecidos do ICHC - FMUSP.

4. Enfermeira membro do Laboratório de Pesquisa em Cultura Celular e Feridas - LIM 04 - HCFMUSP.

5. Professor Titular da Disciplina de Cirurgia Plástica da FMUSP e Diretor Técnico da Divisão de Cirurgia Plástica e Queimados do HCFMUSP.

Endereço para correspondência: César Isaac. LIM04 - Av. Dr. Arnaldo 455 - sala 1363 - Cerqueira Cesar - São Paulo, SP. CEP: 01246-903. cesaris@ plastica.fm.usp.br
} 
$\mathrm{D}$ iabetes mellitus representa um grupo de desordens metabólicas heterogêneas que surge como resultado de hiperglicemia por déficit na secreção e/ou ação da insulina. Incluem-se na definição dois tipos de diabetes: tipo 1, resultante de destruição de células $\beta$-pancreáticas produtoras de insulina; e tipo 2, o qual resulta da resistência periférica à essa enzima ${ }^{1}$.

A prevalência do diabetes vem crescendo em proporções epidêmicas ${ }^{2}$. Atualmente a doença afeta 170 milhões de pessoas no mundo ${ }^{3}$, sendo esperados 430 milhões para 2030. Do mesmo modo, crescem em número os sujeitos às suas complicações, particularmente aquelas de longo prazo, como: doenças cardiovasculares, nefropatia, retinopatia, neuropatia e úlceras nos membros inferiores ${ }^{11}$. Dentre essas afecções, a última é responsável por um maior número de admissões hospitalares ${ }^{2}$, com gastos anuais em relação a seu cuidado chegando a cinco bilhões de dólares nos Estados Unidos ${ }^{4}$. Além disso, estima-se que um em cada quatro pacientes com diabetes irão desenvolver feridas crônicas nos pés em algum momento da vida ${ }^{5}$.

Úlceras nos pacientes diabéticos podem ser definidas como lesões que envolvem perda de epitélio e que podem se estender à derme e camadas mais profundas, algumas vezes envolvendo ossos e músculos ${ }^{2}$. Entretanto, no diabético, úlceras nos pés freqüentemente demoram para cicatrizar devido a uma série de aberrações moleculares e celulares do processo de cicatrização ${ }^{6}$, sendo as principais: alta concentração de metaloproteinases (MMPs), neuropatia, alta probabilidade de infecção e resposta inflamatória não fisiológica, estresse oxidativo, formação excessiva de AGEs (produtos de glicoxidação avançada), neoangiogênese deficiente, desbalanço entre metabolismo e entrega de nutrientes, concentrações inadequadas de fatores de crescimento e reguladores de expressão gênica, e anormalidades celulares ${ }^{6}$.

\section{Alta concentração de MMPs}

Fisiologicamente, proteases (MMPs) que degradam matriz extracelular (MEC) estão sob controle fino de inibidores plasmáticos (ex: alfa2-macroglobulina) ou inibidores teciduais de metaloproteinases (TIMPs) ${ }^{7}$. No entanto, nas feridas crônicas de diabéticos há aumento na concentração de MMP-2, MMP-8 e MMP-9, juntamente com diminuição de TIMPs. Esse desbalanço leva à destruição de proteínas e fatores de crescimento necessários para iniciar a fase proliferativa, contribuindo para estacionar a ferida na fase inflamatória da cicatrização. Como possível explicação para esse fenômeno há evidências sugerindo que macrófagos de diabéticos secretam exageradamente metaloproteinases e que as citocinas IL-1 (interleucina-1), e TNF- $\alpha$ (fator de necrose tumoral- $\alpha$ ) estão em níveis elevados nas feridas em questão. Estes dois últimos sinalizadores têm como uma de suas funções aumentar secreção de proteases e diminuir os inibidores delas ${ }^{1}$.

\section{Neuropatia}

A neuropatia é a origem mais comum de úlceras nos indivíduos diabéticos ${ }^{2}$, com comprometimento de componentes motor, sensorial e autônomo do sistema nervoso periférico ${ }^{7}$. Esse processo como um todo leva à queda na secreção de neuropeptídeos (substância $\mathrm{P}$ e peptídeo relacionado ao gene da calcitonina), o que induz a prejuízos na produção de fatores de crescimento, quimiotaxia e proliferação celulares ${ }^{6}$.

O componente autônomo da neuropatia do diabético induz à queda da resistência pré-capilar, a qual favorece fluxo capilar, aumentando pressão hidrostática luminal e forças de cisalhamento, gerando resposta inflamatória que, por sua vez, causa espessamento na membrana basal do vaso. Esse resultado final compromete a cicatrização por: restringir transporte de nutrientes; induzir queda na capacidade elástica do vaso, com conseqüentes vasodilatação limitada e isquemia funcional; diminuir hiperemia máxima e prejudicar auto-regulação do capilar $^{6,8}$.

A neuropatia diabética sensorial causa insensibilidade aos sintomas protetores contra pressão e calor, o que aumenta a probabilidade de desenvolvimento de úlceras e do crescimento em extensão das já existentes ${ }^{7,9}$.

Já o déficit motor do sistema nervoso periférico acaba criando estresse físico indevido no pé insensível, levando a deformidades anatômicas (exs: pé arqueado, dedos em garra), as quais contribuem para formação de úlceras ${ }^{7}$.

Resposta inflamatória não fisiológica e alta probabilidade de infecção

Úlceras crônicas nos pés costumam estacionar na fase inflamatória, com consequente formação prejudicada do tecido de granulação. Foi sugerido que quanto mais uma ferida permanece na fase inflamatória, maiores quantidades de defeitos microcelulares se acumulam, diminuindo ainda mais a probabilidade de cura ${ }^{6}$.

A hiperglicemia prejudica a eficiência dessa resposta inflamatória por meio de alterações nas funções de neutrófilos, macrófagos e linfócitos. Mais particularmente, macrófagos e neutrófilos tem suas 
capacidades citotóxica e fagocítica deficientes ${ }^{1,8}$. Evidências sugerem que estas alterações nas atividades dessas células sejam devido à baixa pressão de oxigênio local, já que os processos prejudicados consomem altas concentrações desse gás ${ }^{8}$.

Com relação à infecção da ferida, foi levantado que sua incidência em úlceras diabéticas é maior do que em outras feridas crônicas. Isso decore tanto da função diminuída de leucócitos, quanto ao fato de que os normalmente presentes compressão e estresse físico acabam levando a aumento da carga bacteriana local ${ }^{7}$. Também há dados sugerindo que existe aumento mais substancial no número de micro-organismos quando há tecido necrótico. Adicionalmente, uma relação foi estabelecida entre número de bactérias local e cicatrização deficiente: quando mais de $10^{5}$ bactérias são encontradas por grama de tecido, há grande probabilidade de que o reparo tecidual esteja deficiente, com este número caindo para $10^{3}$ quando se tratam de estreptococos $\beta$-hemolíticos ${ }^{8}$.

Desse modo, para combater uma carga bacteriana aumentada seria esperado, fisiologicamente, que houvesse aumento na razão entre linfócitos CD4 e CD8 (CD4/CD8). Entretanto, em uma análise das margens de feridas e úlceras de diabéticos verificou-se diminuição nesta relação, com aumento no número de células CD8 e diminuição das CD4. Esses resultados sugerem que células CD8 possam ter papel ativo na cicatrização deficiente do diabético, já que evidências as levantam como atuantes na alteração prejudicial do reparo tissular fisiológico ${ }^{6}$.

\section{Estresse oxidativo}

Evidências crescentes sugerem ligação causal entre hiperglicemia e estresse oxidativo, o qual leva a danos celulares e várias complicações associadas ao diabetes. Vários mecanismos geram este estresse oxidativo, estando envolvidas: ácido ascórbico (vitamina C), proteína quinase C (PKC), via dos poliois, via da hexosamina e radicais livres de oxigênio 6 .

A hiperglicemia interfere no transporte celular de ácido ascórbico (poderoso antioxidante) em várias células, incluindo fibroblastos. A glicose tem uma estrutura similar a do ácido ascórbico, podendo inibir competitivamente seu transporte pelas membranas celulares ${ }^{8}$.

O diabético também apresenta uma atividade aumentada da PKC, a qual aumenta o estresse oxidativo por ativação da enzima NADPH (nicotinamida adenina dinucleotídeo fosfato reduzido) oxidase e consequente depleção de NADPH. Este último efeito reduz a síntese de NO (óxido nítrico) e glutationa reduzida, aumentando a produção de radicais livres de oxigênio ${ }^{6}$.

As altas concentrações de glicose acabam saturando a enzima hexoquinase da via glicolítica, fazendo com que uma porção deste monossacarídeo acabe seguindo por uma via alternativa de degradação: a via dos poliois, viabilizada pela aldose redutase. Como resultado final, é formado o sorbitol, sendo que as reações que precederam sua formação utilizaram NADPH. Deste modo, a concentração desta última substância acaba diminuindo ainda mais ${ }^{6,10}$.

O diabetes também se caracteriza por aumento da atividade da via biossintética da hexosamina, a qual limita conversão de NADH (nicotinamida adenina dinucleotídeo reduzido) a NADPH por inibição da gliceraldeído-6-fosfato desidrogenase ${ }^{6}$.

Na doença em questão, acréscimo verificado nas atividades da cascata do ácido araquidônico, xantina oxidase, NADPH oxidase e componente semi-ubiquinona da cadeia de transporte de elétrons mitocondrial leva à formação de radicais livres de oxigênio. Entre eles está o superóxido, o qual pode reagir com $\mathrm{NO}$ e dar origem a peroxinitrito, ou ser convertido pela superóxido dismutase a peróxido de nitrogênio. Este último, por sua vez, pode gerar radicais hidroxila, caso esteja na presença de íons cuproso e/ou ferroso ${ }^{6,11}$.

O ânion superóxido limita a biodiversidade de vasodilatadores ao reagir com NO. Já o peroxinitrito contribui para perpetuação da inflamação e apoptose prematura de células produtoras de matriz. Por fim, radicais hidroxila interagem com proteínas, lipídeos e DNA, induzindo condições como: lesão de reperfusão, dementia e aterosclerose.

\section{Formação excessiva de AGEs}

A formação excessiva de AGEs (glicotoxinas) tem sido reconhecida como importante mecanismo patofisiológico das complicações do diabetes. Essas substâncias são produtos de glicoxidação avançada, conjunto de reações que constitui-se de: reação entre grupamentos carbonila de aldeídos e porções $\mathrm{N}$-terminal ou amino-livres de proteínas; formação subsequente de bases de Schiff (instáveis); conversão a produtos Amadori (estável); reações oxidativas em uma pequena parte deste último e, assim, geração

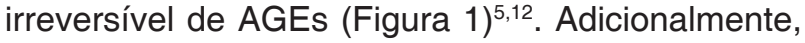
AGEs podem ser gerados por reações entre açúcares e grupos amino de fosfolipídios, e guanil-nucleotídeos do DNA; havendo a possibilidade deles serem formados por fontes não diretamente relacionadas à glicose, como por oxidação de aminoácidos e lipídios ${ }^{13,14}$. 


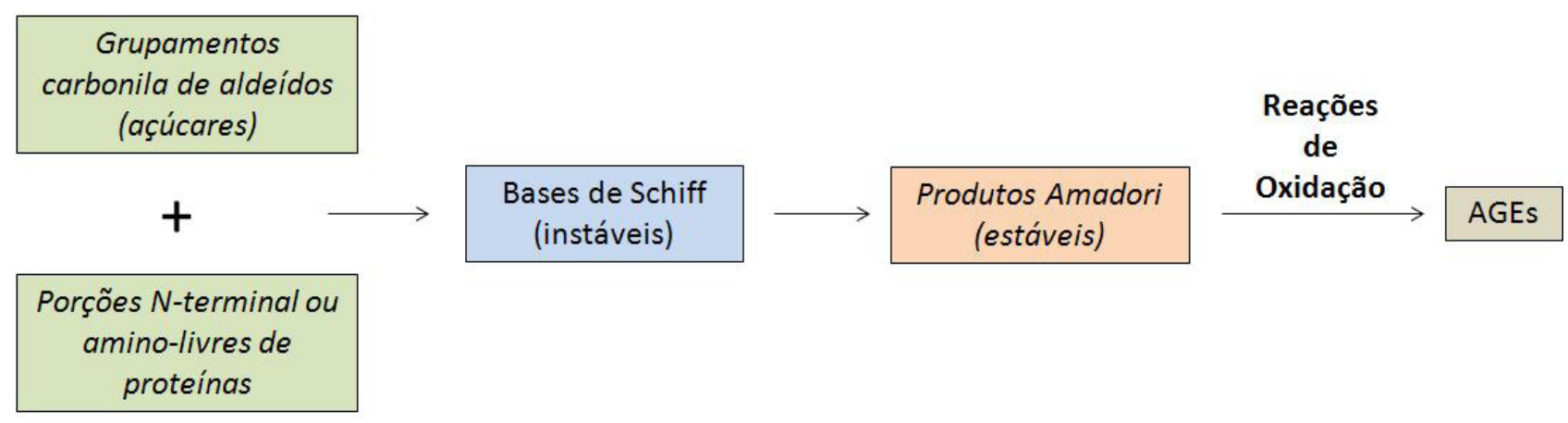

Figura 1. Esquematização da formação de AGEs

A concentração de produtos Amadori se encontra em equilíbrio com a de glicose e, consequentemente, está alta em hiperglicêmicos. Portanto, há também aumento na formação de AGEs nestes indivíduos. Entretanto, no meio intracelular, a glicose tem o menor potencial de glicação entre os açúcares, apresentando maior relevância com relação a essa característica alguns intermediários da via glicolítica e compostos dicarbonil. $\mathrm{O}$ agente glicante mais potente é o metilglioxal, o qual é detoxificado em uma conversão catalisada por glioxidase I e II, e glutationa reduzida ${ }^{5}$.

Apesar de a literatura científica abordar mais formação endógena de AGEs, grande porção dessas substâncias provém de fontes exógenas. Entre elas estão tabaco e alimentos expostos a altas temperaturas ${ }^{5,13,15}$.

Os principais mecanismos de como AGEs estão relacionados às complicações do diabetes são: acúmulo dessas substâncias no meio extracelular, interação com RAGEs (receptor para produtos de glicoxidação avançada) e formação intracelular de glicotoxinas $5,13,16$.

A presença de produtos de glicação na mielina dos nervos periféricos a deixa susceptível à fagocitose por macrófagos, contribuindo para desmielinização segmentar. Além disso, evidências sugerem que os AGEs prejudicam regeneração nervosa ${ }^{5,13}$.

O acúmulo de glicotoxinas no meio extracelular cria ligações-cruzadas aberrantes entre moléculas de colágeno, prejudicando a interação das células com a matriz e, consequentemente, migração celular. Glicação de proteínas matriciais induz também à apoptose, contribuindo para a hipocelularidade verificada nas feridas diabéticas. De modo peculiar, fibroblastos expostos a AGEs não tiveram mudanças na taxa de secreção de colágeno I, mas diminuíram a de ácido hialurônico ${ }^{5,13}$.

Glicotoxinas extracelulares contribuem também para alterar a bioatividade de fatores de crescimento, prejudicando suas estruturas e a de seus receptores ${ }^{13}$.

A interação AGE/RAGE desencadeia cascatas de sinalização intracelular, que culminam, entre outros resultados, com modulação gênica. Por meio desse mecanismo, essas substâncias levam aos efeitos prejudiciais a seguir: falha na neovascularização induzida pela isquemia funcional; espessamento da membrana basal dos vasos; glicação de LDL (lipoproteína de baixa densidade), com prejuízo de sua captação pelo LDLR (receptor de lipoproteína de baixa densidade) e facilitação da fagocitose por macrófagos, contribuindo para formação de células espumosas; estresse oxidativo;

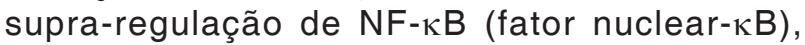
fator de transcrição que aumenta a expressão de citocinas inflamatórias; aumento da expressão de MMPs, TNF- $\alpha$, IL-1,VCAM-1 (molécula de adesão celular vascular-1) e ICAM-1 (molécula de adesão intercelular-1) e infra-regulação de eNOS (NO-sintase endotelial) $)^{13,16}$.

Evidências sugerem que as glicotoxinas formadas intracelularmente também causam deficiências celulares. Um fenômeno em favor dessa afirmação é a modificação do bFGF (fator básico de crescimento dos fibroblastos) nas células endoteliais, com queda na proliferação de fibroblastos e queratinócitos ${ }^{5}$.

\section{Neoangiogênese deficiente}

No reparo tissular fisiológico, fibroblastos, macrófagos e queratinócitos secretam VEGF (fator de crescimento endotelial vascular) na corrente sanguínea, o qual ativa eNOS da medula óssea e, assim, aumenta produção de NO. Esta substância, por sua vez, induz migração de EPCs (células progenitoras endoteliais) para circulação e, por meio da secreção de SDF-1 $\alpha$ (fator derivado de células estromais-1 $\alpha$ ) pelos miofibroblastos e queratinócitos 
da ferida, acabam sendo atraídas para o leito cruento, onde promovem a angiogênese ${ }^{1}$.

No entanto, feridas diabéticas apresentam menor migração de EPCs para circulação, o que consiste com neoangiogênese de baixa intensidade. Usando ratos como modelo, descobriu-se que diabéticos apresentam menor atividade de eNOS e produção de SDF-1a, explicando o fenômeno observado'.

\section{Desbalanço entre metabolismo e entrega de nutrientes}

Parte do metabolismo anormal da úlcera diabética pode ser devido a uma baixa concentração de ATP (trifosfato de adenosina) e de glicose, mas alta de lactato. Ao verificar-se aumento da atividade de macrófagos, fibroblastos e outros leucócitos nas margens de feridas crônicas de diabéticos, sugeriu-se que incompatibilidade entre aumento do metabolismo celular e entrega insuficiente de nutrientes pode contribuir substancialmente para a deficiência na cicatrização ${ }^{6}$.

Concentrações inadequadas de fatores de crescimento e reguladores de expressão gênica

Com relação à presença de fatores de crescimento nas úlceras diabéticas, verificouse diminuição na expressão de: PDGF (fator de crescimento derivado de plaquetas), FGF (fator de crescimento dos fibroblastos), IGF-1 (fator de crescimento semelhante à insulina-1), IL-8 (interleucina-8), IL-10 (interleucina-10), esteopontina e TGF- $\beta 1$ (fator transformador do crescimento- $\beta 1$ ). Por outro lado, constatou-se supra-regulação de: IL-1, TNF- $\alpha$ e angiopoietina- $2^{1,17}$.

Concentrações diminuídas de esteopontina e aumentadas de angiopoietina-2 condizem com o atraso na angiogênese, já que a primeira induz o

\section{REFERÊNCIAS}

1. Rafehi H, El-Osta A, Karagiannis TC. Genetic and epigenetic events in diabetic wound healing. Int Wound J. 2010;8:12-21.

2. Rarthur HM, Boulton AJM. The diabetic foot. Clin Dermatol. 2007;25:109-20.

3. Brem H, Tomic-Canic M. Cellular and molecular basis of wound healing in diabetes. J Clin Invest. 2007;117:1219-22.

4. Bowering CK. Diabetic foot ulcers. Pathophysiology, assessment, and therapy. Can Family Phys. 2001;47:1007-16. processo e a segunda o inibe ${ }^{1}$.

Recentemente têm-se descoberto também um papel importante do Micro RNA na patologia das feridas crônicas do diabético. Fisiologicamente, um precursor de Micro RNA é convertido pela enzima Dicer à Micro RNA, o qual tem como função inibir tradução de RNAs mensageiros específicos ${ }^{18}$.

Ao analisarem-se ratos diabéticos e não diabéticos, verificou-se diminuição em $40 \%$ da enzima Dicer no primeiro grupo, sugerindo uma mudança substancial na expressão gênica celular. Também se descobriu que mecanismos biológicos relacionados ao mecanismo descrito podem ter papel direto na queda de proliferação de queratinócitos na úlcera diabética. HIF-1a (fator induzidor de hipóxia-1a) é um fator de transcrição supra-regulado no diabetes e que estimula expressão do Micro RNA 210. Este, por sua vez, inibe expressão do gene que codifica o fator de transcrição E2F3, que estimula atividade mitótica de queratinócitos. Simplificadamente, aumento na concentração de HIF-1 $\alpha$ inibe proliferação de queratinócitos ${ }^{1}$.

\section{Anormalidades celulares}

Os queratinócitos e fibroblastos de úlceras de diabéticos apresentam fenótipos diferentes dos de feridas de pessoas saudáveis. Os primeiros têm habilidades alteradas de migração, proliferação, diferenciação e secreção de fatores de crescimento, enquanto os últimos apresentam: alterações na morfologia, senescência, diferenciação deficiente em miofibroblasto, baixas capacidades migratória e proliferativa, e função secretora aberrante ${ }^{1,3,13}$.

Dado os grandes avanços na compreensão científica da cicatrização fisiológica e dos mecanismos das feridas crônicas de diabéticos, novas abordagens da patologia poderão fornecer resultados mais satisfatórios ao seu tratamento ${ }^{7}$.
5. Huijberts MSP, Schaper NC, Schalkwijk. Advanced glycation end products and diabetic foot disease. Diabetes Metab Res Rev.2008;24(Suppl 1):S19-S24.

6. Sibbald RG, Woo KY. The biology of chronic foot ulcers in persons with diabetes. Diabetes Metab Res Rev. 2008;24(Suppl 1):S25-S30.

7. Falanga V. Wound healing and its impairment in the diabetic foot. Lancet. 2005;366:1736-43.

8. Guyton GP, Saltzman CL. The diabetic foot. Basic mechanisms of disease. J Bone Joint Surg. 2001;83:1084-96. 
Ladeira et al. Úlceras nos membros inferiores de pacientes diabéticos.

9. Jeffcoate WJ, Price P, Harding KG. Wound healing and treatments for people with diabetic foot ulcers. Diabetes Metab Res Rev. 2004;20(Suppl 1):S78-S89.

10. Corrêa-Giannella ML, Vieira MS. A predisposição genética para o desenvolvimento da microangiopatia no DM1. Arq Bras Endocrinol Metab. 2008;52(2):375-86.

11. Schneider CD, Oliveira AR. Radicais livres de oxigênio e exercício: mecanismos de formação e adaptação ao treinamento físico. Rev Bras Med Esporte. 2004;10:308-13.

12. Pageon $\mathrm{H}$. Reaction of glycation and human skin: the effects on the skin and its components, reconstructed skin as a model. Pathol Biol. 2010;58:226-31.

13. Peppa M, Stavroulakis $P$, Raptis SA. Advanced glycoxidation products and impaired diabetic wound healing. Wound Repair Regen. 2009;17:461-72.

14. Goh SY, Cooper ME. The role of advanced glycation end products in progression and complications of diabetes. J Clin Endocrinol Metab. 2008;93:1143-52.
15. Koschinsky T, He CJ, Mitsuhashi T, Bucala R, Liu C, Buenting C, Heitmann K, Vlassara H. Orally absorbed reactive glycation products (glycotoxins): an environmental risk factor in diabetic neuropathy. Proc Nat Acad Sci. 1997;94:6474-9.

16. Ashmed N. Advanced glycation endproducts - role in pathology of diabetic complications. Diabetes Res Clin Pract. 2005;67:3-21.

17. Blakytny R, Jude $E$. The molecular biology of chronic wounds and delayed healing in diabetes. Diabetic Med. 2006;23:594-608.

18. Wang J-M, Tao J, Chen AF. Abstract 1958: microRNA Mir-27b rescues impaired angiogenic function of endothelial progenitor cells and accelerates wound healing in type 2 diabetes. Circulation. 2008;118:S 412.

Artigo recebido em: 03/05/2011

Artigo aceito em: 08/07/2011 